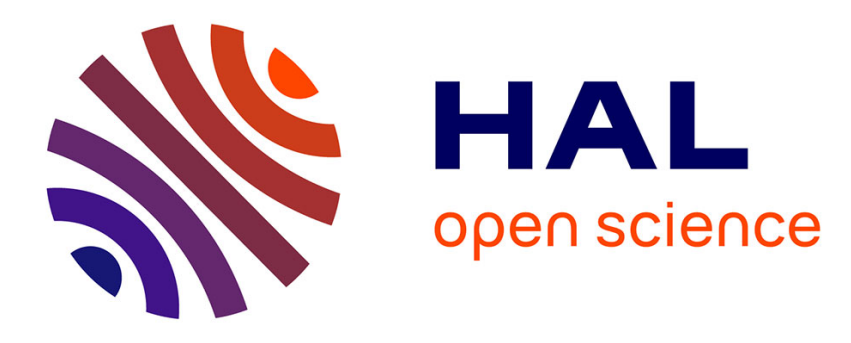

\title{
Thermal diffusivities of thin films measured by transient thermal gratings
}

O. Käding, H. Skurk, E. Matthias

\section{To cite this version:}

O. Käding, H. Skurk, E. Matthias. Thermal diffusivities of thin films measured by transient thermal gratings. Journal de Physique IV Proceedings, 1994, 04 (C7), pp.C7-619-C7-622. 10.1051/jp4:19947146 . jpa-00253204

\section{HAL Id: jpa-00253204 https://hal.science/jpa-00253204}

Submitted on 1 Jan 1994

HAL is a multi-disciplinary open access archive for the deposit and dissemination of scientific research documents, whether they are published or not. The documents may come from teaching and research institutions in France or abroad, or from public or private research centers.
L'archive ouverte pluridisciplinaire HAL, est destinée au dépôt et à la diffusion de documents scientifiques de niveau recherche, publiés ou non, émanant des établissements d'enseignement et de recherche français ou étrangers, des laboratoires publics ou privés. 


\title{
Thermal diffusivities of thin films measured by transient thermal gratings
}

\author{
O.W. Käding(1), H. Skurk and E. Matthias \\ Fachbereich Physik, Freie Universität Berlin, Arnimallee 14, 14195 Berlin, Germany
}

\begin{abstract}
Transient thermal gratings have been utilized for investigating heat diffusion in thin films. The gratings were observed by either the displacement technique or by thermoreflectance. Both observation modes allow a quantitative determination of lateral diffusivities. Spatial resolution in the $\mu \mathrm{m}$ range can be obtained, even for films with large thermal diffusivities. Results of thermal diffusivitiy measurements arē presented for thin $\mathrm{Au}-, \mathrm{Cr}-$, and $\mathrm{Ni}$-films, sputtered onto the quartz substrates with different thicknesses between $100 \mathrm{~nm}$ and $3 \mu \mathrm{m}$.
\end{abstract}

\section{INTRODUCTION}

Thermal diffusivities of thin films are of interest for several reasons. They are a criterion for the film quality, they are important when using films for channelling or spreading heat, and they are also essential for the resistivity of films against high intensity radiation. Photothermal methods are well suited for thermal chracterization of thin films since they are nondestructive and need no sample preparation. The basic requirement for thermal measurements of thin films is a local response in order to minimize thermal substrate influences.

In order to achieve local information about thermal diffusivities of thin films, we applied displacement and thermoreflectance detection of transient thermal gratings (TTGs). Earlier, displacement measurements employing TTGs have been carried out with glasses, $\mathrm{Si}^{1}$ and metals ${ }^{2}$, mainly to demonstrate the technique. Now, TTGs are routinely used for characterizing thin metal films ${ }^{3}$, thin diamond films on substrates ${ }^{4}$, and for thermal depth-profiling of thick free-standing diamond films $s^{5}$. In this contribution, the experimental techniques are briefly described and results obtained for thin metal films are presented.

\section{EXPERIMENTAL TECHNIQUES}

The principal scheme of the TTG technique is shown in Fig. 1. The light of a pulsed pump laser is split into two beams which are reunited in the surface plane. The resulting interference pattern with periodicity $\Lambda$ generates a temperature pattern when the laser light is absorbed. This periodic temperature variation causes a corresponding surface deformation that acts like a grating.

(1) Present address: Daimler-Benz AG, Materials Research Lab., Wilhelm-Runge-Strasse 11, 89081 Ulm, Germany 


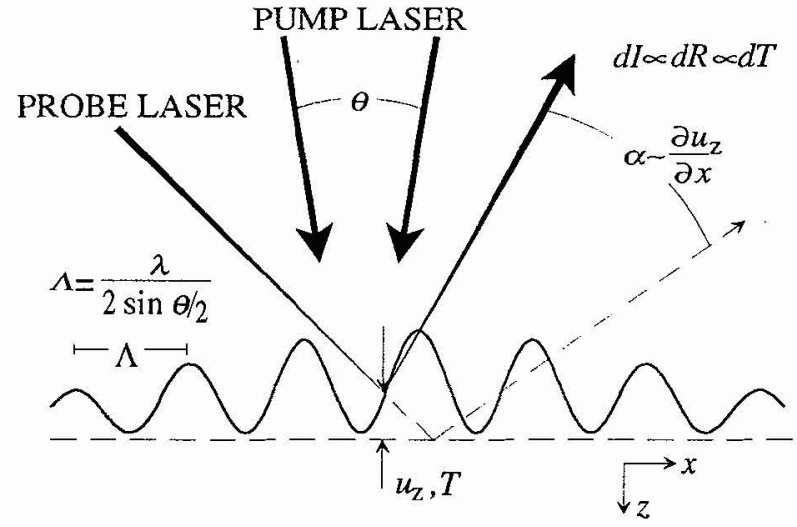

Fig. 1: Principle of displacement and thermoreflectance detection of TTGs. Typical dimensions are $\Lambda=16 \ldots 300 \mu \mathrm{m}, T_{\max } \approx 10 \mathrm{~K}$, $u_{z, \max } \approx 1 \AA$.
The temperature relaxation, governed by the thermal diffusivity, can be detected by monitoring the decay of the surface displacement or the thermoreflectance. For displacement measurements a $\mathrm{cw}$ laser probe beam is tightly focused on a given grating slope. The reflected light is guided to a position sensitive photodetector, which measures the deflection angle and thus the derivative of the grating. For bulk materials, the displacement relaxation is exponential with a time constant

$$
\tau=\frac{\Lambda^{2}}{4 \pi^{2} \kappa_{x}},
$$

determined only by the lateral thermal diffusivity, $\kappa_{\mathrm{x}}$, and the grating period $\Lambda$. Such simple transient behavior also

holds for self supporting films or those of sufficient thickness. For thin layers and multilayer systems, the mathematical analysis of heat diffusion and thermal expansion leads to expressions which are considerably more complex. To illustrate the signal shape, a time-resolved scan across several central grating grooves of a Au film on quartz glass is shown in Fig. 2a. While the nearly exponential decay is independent of the grating phase, the amplitude reflects the periodicity of the grating. Thus, analysis of the decay time is independent of the exact alignment between pump and probe laser.

The analysis of thermoreflectance data avoids the difficult formalism of thermoelastic coupling. It probes the temperature directly be measuring thermally induced surface reflectivity changes. A typical time-resolved thermoreflectance scan is shown in Fig. $2 \mathrm{~b}$. When focusing the probe laser on an initially cold minimum, thermoreflectance selectively detects the lateral heat diffusion. The arrival of heat in the grating minima is given by a $(1-\exp (-\mathrm{t} / \tau))$ characteristic. The relaxation of a grating maximum due to vertical heat flux varies with $(t)^{-1 / 2}$, again a simple dependence. Thermoreflectance detection should be favored whenever possible, since no complicated thermoelastic effects are involved. On the other hand, the signal size is significantly smaller than that for displacement signals and depends strongly on the thermo-optical behavior of the material. In addition, one has to carefully watch the alignment between
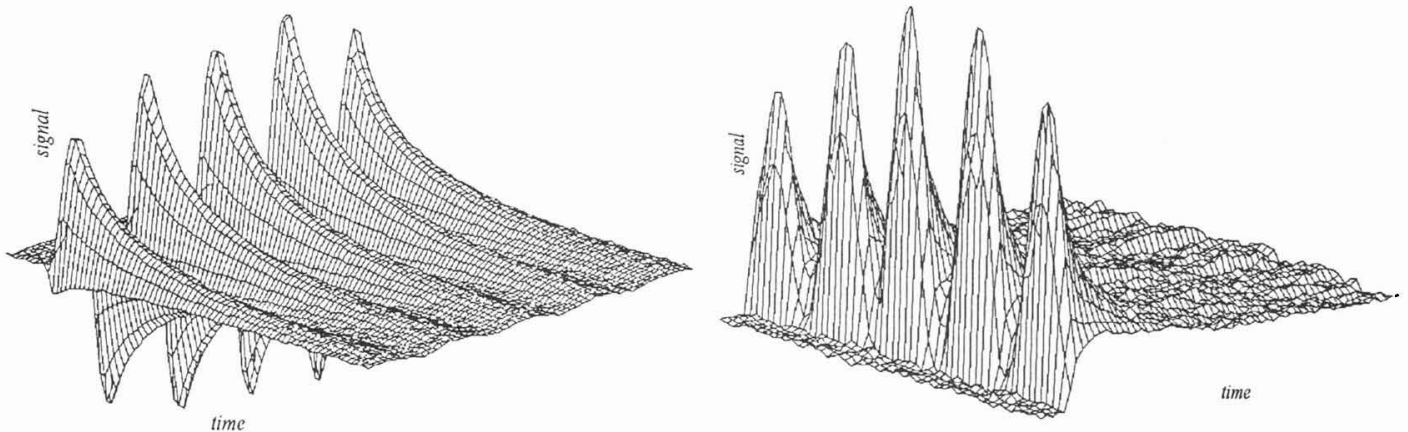

Fig. 2a: Time decay of the displacement grating vs. the Fig. 2b: Time decay of the surface temperature pattern position of the probe beam along the grating axis recorded measured across the grating by thermoreflectance. with a $1060 \mathrm{~nm}$ Au film on fused silica. The size of one mesh Parameters are the same as in Fig. $2 \mathrm{a}$. is $5.9 \mu \mathrm{m} \times 200 \mathrm{~ns}$. 
pump and probe beam. Therefore, thermoreflectance is generally used only as a cross-check to support the validity of the results obtained from displacement measurements.

There are two ways to analyze the decay rate of the displacement for inhomogenous samples, like thin film/substrate composites. Firstly, a complete mathematical analysis of the decay time based on the knowledge of film and substrate properties yield the film diffusivity. For this, knowledge about the thermal contact resistance between film and substrate is required. A second and more intuitive analysis is to compare an exponential function to the data, as it would apply to homogenous materials. In this case, diffusivity values should be called 'effective' diffusivities since they are averaged over film and substrate.

Besides lateral heat diffusion, the vertical penetration depth can be described by the diffusion length $\mathrm{L}_{\mathrm{th}}=\left(4 \kappa_{2} \tau\right)^{1 / 2}$, where $\kappa_{\mathrm{z}}$ is the vertical diffusivity and $\tau$ the relaxation time of the lateral heat diffusion. Therefore, varying the grating period allows to measure the effective lateral thermal diffusivity averaged over different depths. For inhomogenous or layered structures, this means that for small $\Lambda$ (film thickness $\left.d>L_{t h}\right)$ the measured diffusivity is mainly determined by the film value, whereas for larger $\Lambda\left(d<L_{t h}\right)$ the diffusivity of the film/substrate system is obtained. In the limit of very large $\Lambda$ ( $\left.d \ll L_{t h}\right)$ and large substrate thickness compared to the film thickness, the measured diffusivity only represents the value of the substrate. Taking these effects into account, measurements using TTGs enable the separation of film and substrate influence on the thermal properties of a layer/substrate system.

An example of the variation of the effective diffusivity of a $275 \mathrm{~nm}$ Ni film on a fused silica substrate as a function of grating constant is given in Fig. 3. The effective diffusivity, recorded by the displacement relaxation, decreases with increasing grating period, indicating a much poorer substrate diffusivity than that of the film. Towards smaller $\Lambda$, the effective diffusivity increases and should for $\Lambda \rightarrow 0$ approach the film diffusivity which is obtained from a complete analysis using the multilayer model.

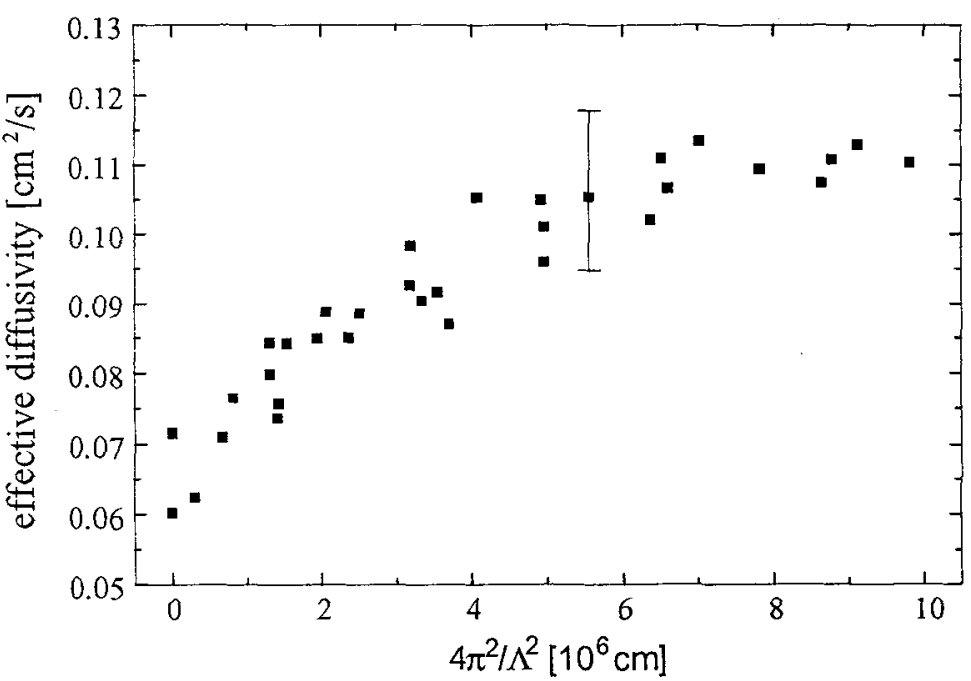

Fig. 3: Effective diffusivities for $275 \mathrm{~nm} \mathrm{Ni}$ on fused quartz $v s$. the grating constant, obtained by the displacement technique.

\section{RESULTS}

Thin metal ( $\mathrm{Au}, \mathrm{Cr}$ and $\mathrm{Ni}$ ) films with thicknesses between $100 \mathrm{~nm}$ and $3 \mu \mathrm{m}$, sputter-deposited on fused silica, have been investigated. The gold films were sputtered on a chromium intermediate layer of $20 \mathrm{~nm}$ thickness in order to achieve good adhesion. Measurements were performed in both observation modes, displacement and thermoeflectance. In order to analyze the lateral thermal film diffusivities with the multilayer model, independent measurements of thermal contact resistances between the metal and the quartz substrate were needed and carried out by means of a different transient thermoreflectance technique, to be described elsewhere ${ }^{6}$. For $\mathrm{Cr}$ and $\mathrm{Ni}$ films the interface resistances are found to be well below $10^{-7} \mathrm{Km}^{2} / \mathrm{W}$, and therefore neglible for thermal analysis. For the $\mathrm{Au} / \mathrm{Cr} /$ quartz composites, however, larger interface resistances of about $1.3 \times 10^{-7} \mathrm{Km}^{2} / \mathrm{W}$ were obtained. This is suggested to be caused by 
adding an interface, by the smaller thermal diffusivity of $\mathrm{Cr}$, and by a poor structural quality of the sputtered gold film in the initial stage of growth.

In Fig. 4 the thickness dependence of lateral thermal diffusivities of the metal films is displayed. For $\mathrm{Ni}$ and $\mathrm{Cr}$ films, no significant change with thickness was observed within the experimental uncertainties. Comparing these results with literature values for $\mathrm{Ni}$ and $\mathrm{Cr}$ bulk $\left(\kappa_{\mathrm{Ni}}=0.23 \mathrm{~cm}^{2} / \mathrm{s}\right.$, $\kappa_{\mathrm{Cr}}=0.30 \mathrm{~cm}^{2} / \mathrm{s}$ ), a high quality of these films can be certified. For Au films, on the other hand, a strong variation of lateral thermal diffusivity with film thickness was found. The values sharply drop with decreasing film thickness. Even for larger film thicknesses, the measured values are clearly below the literature bulk value of $\kappa_{\mathrm{Au}}=1.28 \mathrm{~cm}^{2} / \mathrm{s}$, indicating a poor quality of the sputtered $\mathrm{Au}$ films. These observations confirm the common experience that the microscopic film quality of sputtered $\mathrm{Au}$ is poorer than the one of $\mathrm{Ni}$ and $\mathrm{Cr}$. In general, thermal properties of high-conducting films are stronger influenced by imperfect growth than those of poorly conducting ones.

Acknowledgements: This work was supported by the Deutsche Forschungsgemeinschaft, SFB 337. The authors are grateful to Dr. E. Neske, FhG-IpM Freiburg, for providing the Ni and $\mathrm{Cr}$ films.

* present address: Daimler-Benz AG, Materials Reasearch Lab., Wilhelm-Runge-Straße 11, 89081 Ulm (Germany)

[1] Harata A., Nishimura H., and Sawada T., Appl. Phys. Lett. 57,(1990) 132 - 134

[2] Jáuregui J. and Matthias E., Appl. Phys. A 54, (1992) 35 - 39

[3] Matthias E., Reichling M., Siegel J., Käding O.W., Skurk H., Bizenberger P., and Neske J., Appl. Phys. A 57, (1994), in print

[4] Käding O.W., Matthias E., Zachai R., Füßer H.-J., and Münzinger P., Diamond and Rel. Mat. 2, (1993) $1185-1190$

[5] Käding O.W., Rösler M., Zachai R., Füßer H.-J., and Matthias E., Diamond and Rel. Mat. 3, (1994), in print

[6] Skurk H., Käding O.W. to be published 